\title{
Life Cycle Assessment of Artificial Wetland Systems for Rural Wastewater Treatment
}

\author{
Siyi Wang ${ }^{1}$, Zixiang $\mathrm{Ji}^{2}$ and Yumin $\mathrm{Wang}^{1, *}$ \\ ${ }^{1}$ School of Energy and Environment, Southeast University, Nanjing, China \\ ${ }^{2}$ Jinling high school, Nanjing 210005, China
}

\begin{abstract}
Decentralized wastewater treatment technology, especially natural ecological treatment technology has widely been used in rural regions. In this paper, a comprehensive life cycle assessment (LCA) of a typical wastewater ecological treatment technology - artificial wetland technology was conducted. SimaPro software was applied to simulate the wastewater treatment facility, and the CML2 baseline2000 impact evaluation method was selected to analyze the environmental loads and benefits during the life cycle. The environmental impact of the facility adopting grey-black separation mode is compared with that of the unified collection and treatment model to provide scientific basis and suggestions for the selection of wastewater collection and treatment model. The results indicated that the main environmental impact of the Southeast University artificial wetland system comes from the construction and operation of the artificial wetland and aeration tank. Marine water ecotoxicity is the main impact factor, followed by freshwater water ecotoxicity.
\end{abstract}

\section{Introduction}

With the urbanization of the world and the increasing amount of domestic water, the construction of municipal wastewater treatment facilities also gradually accelerated, which leads to the relatively higher treatment rate of urban wastewater. However, the treatment rate of scattered rural sewage is still lower. At present, decentralized wastewater treatment technologies mainly ecological treatment technologies have been widely applied in rural areas. Life cycle assessment (LCA) had been applied to the environmental impact of different domestic wastewater treatment technologies. Meneses (2010) used LCA to evaluate different disinfection treatments (chlorination plus ultraviolet treatment, ozonation and ozonation plus hydrogen peroxide) and to assess the environmental advantages and drawbacks of urban wastewater reuse for different disinfection treatments. Carolina et al (2015) applied LCA methodology to compare the environmental impacts associated with the treatment of malodorous emissions from two biological treatments, namely biofilter (BF) and biotrickling filter (BTF), two physical/chemical alternatives, namely activated carbon tower (AC) and chemical scrubber (CS), and a hybrid combination of BTF + AC. Suh et al (2002) carried out LCA in order to compare the environmental impacts of five alternative treatment scenarios of sewage sludge in the French context. The scenarios were composed

\footnotetext{
* Corresponding author: wangyumin@seu.edu.cn
} 
of one main process (incineration, agricultural land application, or landfill), one stabilization process (lime stabilization, composting, or anaerobic digestion) and transports of sludge. The study result showed the combination of anaerobic digestion and agricultural land application was most environmentally friendly tanks to less emissions and less consumption of energy. Enrica et al (2011) investigated and compared technical, economic and environmental aspects of four scenarios of sludge treatment wetlands (STW) : 1) STW with direct land application of biosolids, 2) STW with compost post-treatment, 3) centrifuge with compost post-treatment and 4) sludge transport to an intensive wastewater treatment plant. The results show that STW with direct land application is the most costeffective scenario, which is also characterized by the lowest environmental impact. Fuchs et al (2011) used LCA to compare the environmental impacts of vertical flow constructed wetlands (VFCW) and horizontal flow constructed wetlands (HFCW). Corbella et al (2017) carried out LCA to assess the environmental impact of microbial fuel cells implemented in constructed wetlands. The results indicated that the constructed wetland system coupled with graphite-based anode microbial fuel cells appeared as the most environmentally friendly solution which can replace conventional constructed wetlands reducing system footprint by up to $20 \%$. Rebello et al (2021) proposed a guideline framework for LCA of unban wastewater treatment plants based on the shortcomings and good practices identified in the literature reviewed. However, comprehensive life cycle assessment (LCA) of rural decentralized wastewater treatment technologies was seldom performed.

\section{Method}

Life Cycle Assessment (LCA) is a process that evaluates the environmental load associated with a product, process or activity throughout its life cycle from raw material collection, through production, transportation, distribution, use, reuse, maintenance and final disposal of the product (Corominas et al. 2013). The LCA implementation steps was divided into four parts: goal and scope definition, inventory analysis, impact assessment, and result interpretation.

Goal and scope definition

The goals of LCAs usually divided into the following: to build a life-cycle database of the process; to identify the environmental improvement potential of the process; and for the comparison of process schemes. Scoping needs to consider the functions of the product system, functional units, system boundaries, raw data quality requirements, constraints and other detailed information. System boundaries comprised input and output flows of material and energy resources for the construction and operation of these systems (García and Corzo 2008; Yildirim and Topkaya 2012).

Inventory analysis

A complete lifecycle inventory analysis provides an overall estimate of all systemrelated inputs and outputs throughout the lifecycle. For the wastewater treatment system, its inventory considers the production and transportation of building materials and equipment in the construction phase, excavation of the earth in the construction area, and electricity consumption, pollutant discharge and sludge transportation and treatment in the operation phase.

Impact assessment

The impact assessment can be divided into three steps: classification, characterization and quantification (ref). Impact classification is the process of assigning data from inventory analysis to different environmental impact types. The quantification determines the relative magnitude or weight of the contribution of different environmental impact types so that a single indicator can be obtained which is data-driven and comparable. The most 
commonly used quantification method for LCA of wastewater treatment plants is the analytical hierarchy process (AHP).

Interpretation

The interpretation of results aims to analyze the results of the life cycle inventory and impact assessment, explain their deficiencies and draw correct conclusions and make sound recommendations, as well as to align the results of each stage of LCA with the defined goal and scope of the study.

Life cycle assessment tools

In this paper, we will apply Simapro software for LCA analysis (Pre-sustainability 2014). Simapro has a rich database of environmental loads built in, such as ETH-ESU96 for the energy, power, and transportation segments, Dutch concrete for cement and concrete, construction materials and process-related segments of IVAM, etc. It also provides a variety of widely accepted and used evaluation methods such as ECO-Indicator99, EOCindicator95, Ecopoints97, CML92, CML2(2001) EDIP/UMIP, EPS2000, etc.

\section{Results}

The characterization and standardized results of the life cycle impact assessment were calculated after assembling each structure and treatment phase as shown in Figs. 1-2. The main part that causes human toxicity impact is the construction and operation of the aeration tank, and the reason is that the main construction material of the aeration tank is steel plate. While the part that mainly causes the impact of abiotic depletion is the construction and operation of the constructed wetland, and the reason is that the main construction material type of the constructed wetland is light concrete.

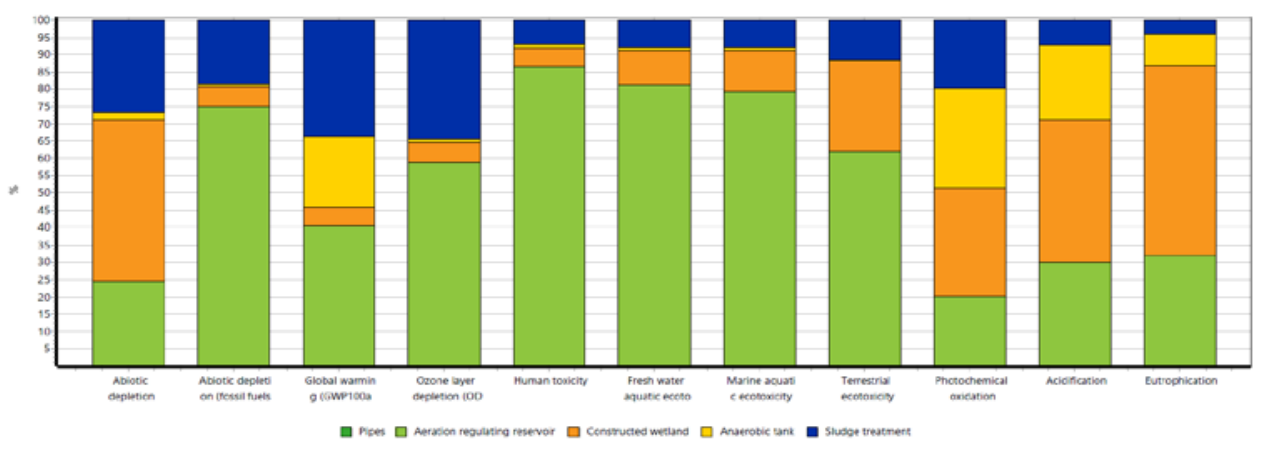

Fig. 1. Histogram of characterization analysis of the constructed wetland system

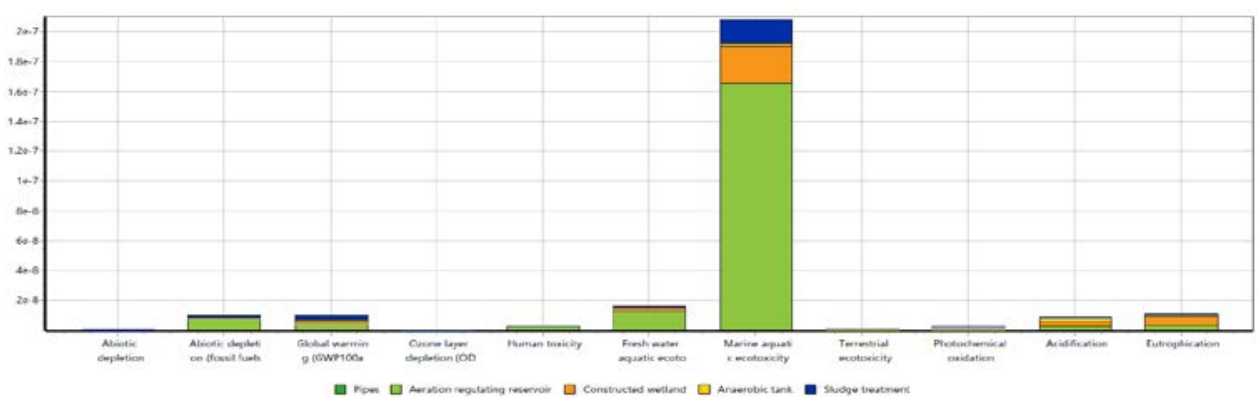

Fig. 2. Histogram of standardized analysis of the constructed wetland system 
The standardized data obtained by further normalizing the characterized data (Fig 2) shows that marine water ecotoxicity is the main impact factor, accounting for $76.8 \%$ of all environmental impact indicators, followed by freshwater water ecotoxicity, accounting for $6.0 \%$ of the overall environmental impact value.

The main environmental impacts are caused by the construction and operation of the artificial wetland and the aeration regulating reservoir throughout the life cycle (shown in Fig. 3). The operation phase of the aeration regulating reservoir includes the treatment of sludge, which occupies the main impact. While the impact of the constructed wetland mainly comes from the acquisition, production and transportation of raw materials during the construction phase. The environmental impact caused by the anaerobic tank only accounts for $2.22 \%$ of the total impact.

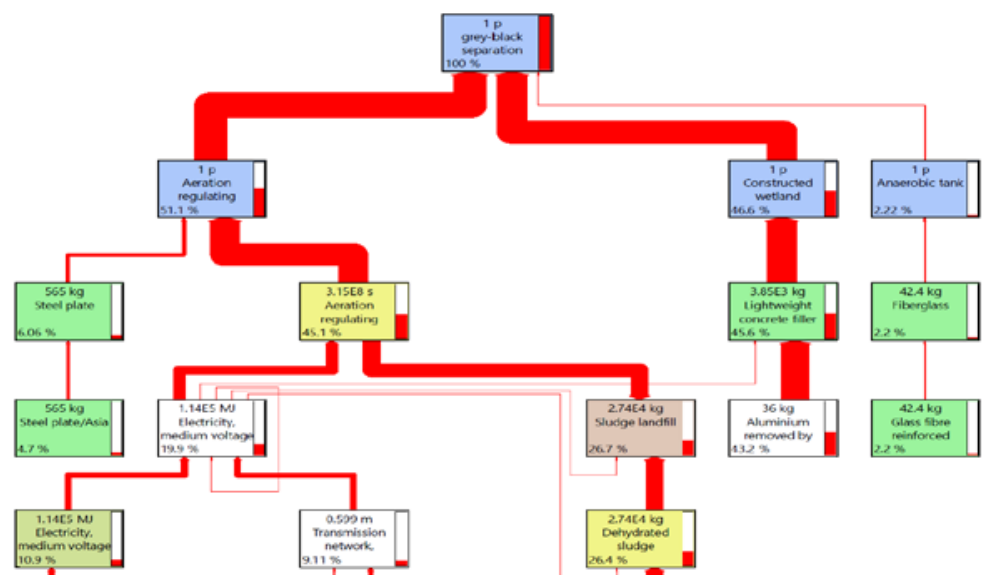

Fig. 3. Reticulation of the life cycle of the constructed wetland system

The marine water ecotoxicity factor in the environmental impact accounts for $76.8 \%$. If the sludge discharge is listed as a separate segment, the segment with $79.3 \%$ contribution to this factor is the construction phase of the aeration tank, followed by the construction and operation of the constructed wetland.

Further process contribution analysis (Fig. 4) shows that more than $60 \%$ of the pollution is generated from landfill disposal of tailings and coal-fired power generation processes, while the disposal of waste gypsum and vehicle transportation also contribute partially.
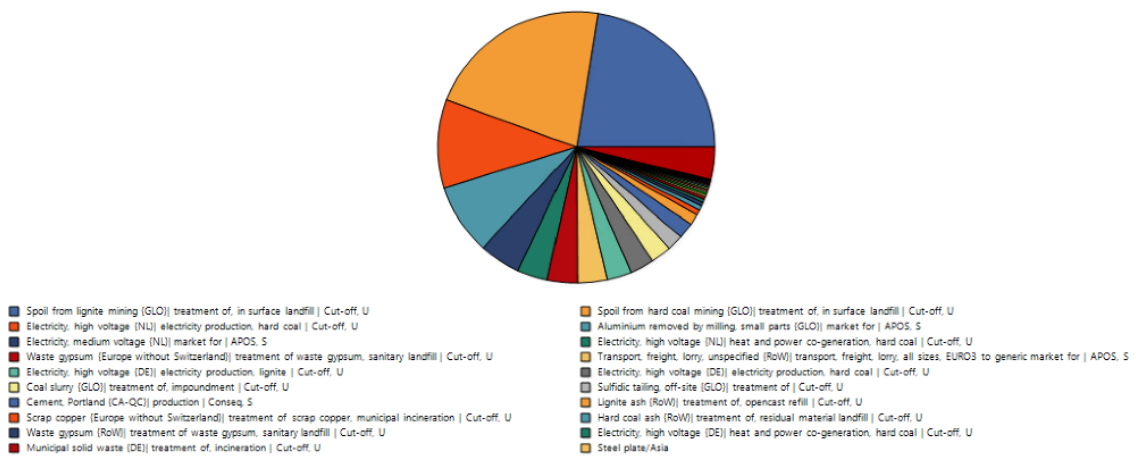

Fig. 4. Sector map of the process contributions to the marine aquatic ecotoxicity 
Freshwater water ecotoxicity accounted for $6.0 \%$ of the overall environmental impact, with the construction phase of the aeration regulating reservoir comprising $81.3 \%$ of the contribution to this factor, followed by the constructed wetland. The process contribution analysis (Fig. 5) shows that similar to the marine water ecotoxicity factor, most of the pollution is generated by the landfill disposal of tailings and the coal-fired power generation process, the difference is that the disposal of waste copper blocks also contributes nearly $10 \%$ to the freshwater water ecotoxicity.
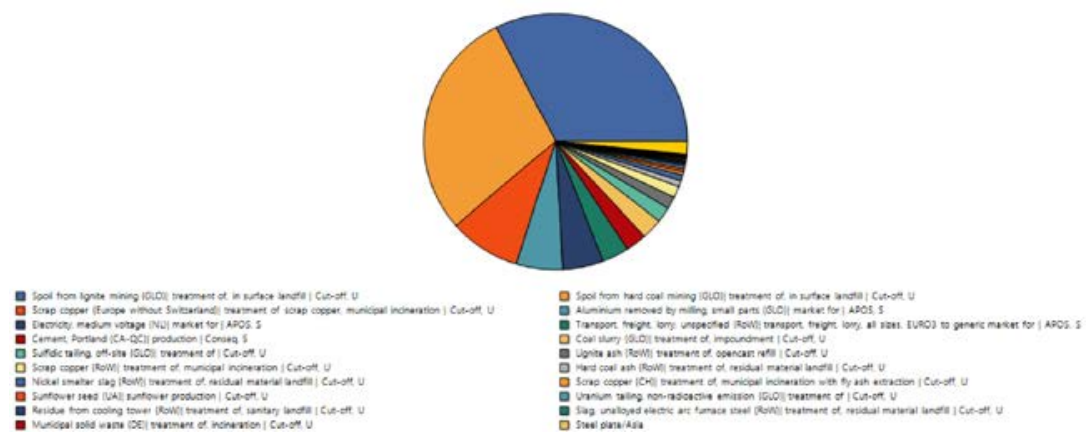

Fig. 5. Sector map of the process contributions to the fresh water aquatic ecotoxicity

\section{Conclusions}

In this paper, the facilities of the typical process of constructed wetland for this life cycle study of rural ecological wastewater treatment system were identified through the research at Southeast University. The environmental loads and environmental benefits generated during the construction and operation phases are analyzed with the method of quantitative analysis. The results indicated that the main environmental impact is caused by the construction and operation of the constructed wetland (46.6\%) and the aeration reservoir (51.1\%) segments. In addition, marine aquatic ecotoxicity is the main impact factor, accounting for $76.8 \%$ of all environmental impact indicators. Next is freshwater aquatic ecotoxicity, accounting for $6.0 \%$ of the overall environmental impact value. The eleven environmental impact indicators values for the constructed wetland system designed with the unified collection mode are all higher than the gray-black separation mode, most notably the global warming and acidification effect indicators are $21 \%$ and $22 \%$ higher, respectively. As the treatment scale of rural decentralized wastewater treatment facilities is very small, does not involve the traditional steel, cement, masonry industry's high energy consumption, heavy pollution production process, so the environmental impact is mainly manifested in the construction phase during the entire life cycle. The results obtained can help managers make scientific and reasonable rural wastewater treatment strategies.

\section{Acknowledgements}

This work was funded by key research and development plan of Anhui Province (Grant No. 202004a06020026). 


\section{References}

[1] Carolina A, Raquel L. Jose M E, et a1. Selection of odour removal technologies in wastewater treatment plants: A guideline based on Life Cycle Assessment[J]. Journal of Environmental Management, 2015, 149: 77-84.

[2] Corbella Clara, Puigagut Jaume, Garfí Marianna. Life cycle assessment of constructed wetland systems for wastewater treatment coupled with microbial fuel cells. Science of the Total Environment, 584-585: 355-362.

[3] Enrica U, Ivet F Jordi M, et a1. Technical, economic and environmental assessment of sludge treatment wetlands[J]. Water Research, 2011, 45: 573-582.

[4] Fuchs, VJ, Mihelcic, JR, Gierke, JS. Life cycle assessment of vertical and horizontal flow constructed wetlands for wastewater treatment considering nitrogen and carbon greenhouse gas emissions[J]. Water Research, 2011, 45: 2073-2081.

[5] García, J., Corzo, A. 2008. Depuracion con Humedales Construidos. Universidad Politecnica de Cataluna, pp. 1-96.

[6] Ll. Corominas, J. Foley, J.S. Guest, A. Hospido, H.F. Larsen, S. Morera, A. Shaw, Life cycle assessment applied to wastewater treatment: State of the art, Water Research, Volume 47, Issue 15, 2013: 5480-5492.

[7] Meneses M. Environmental assessment of urban wastewater reuse: Treatment alternative and applications [J]. Chemosphere, 2010, 81: 266-272.

[8] Pre-sustainability, 2014. https://www.pre-sustainability.com/simapro (Accessed 21 March 2016).

[9] Rebello Thais Ayres, Roque Regiane Pereira, Gonçalves, Ricardo Franci, et al. Life cycle assessment of urban wastewater treatment plants: a critical analysis and guideline proposal. [J]. Water Science \& Technology, 2021, 83 (3): 501-514.

[10] Suh YJ, Rousseaux, P. An LCA of alternative wastewater sludge treatment scenarios [J]. Resources, Conservation and Recycling, 2002, 35: 191-200.

[11] Yildirim, M., Topkaya, B. 2012. Assessing environmental impacts of wastewater treatment alternatives for small-scale communities. Clean. e Soil, Air, Water 40 (2), 171-178. 